\title{
Can Social Media Influence the Buying Choices of Shoppers
}

\author{
Shrey Kaushik
}

Amity Business School, Amity University

\section{To Cite this Article}

Shrey Kaushik, "Can Social Media Influence the Buying Choices of Shoppers", International Journal for Modern Trends in Science and Technology, 6(8): 141-146, 2020.

Article Info

Received on 02-July-2020, Revised on 25-July-2020, Accepted on 02-August-2020, Published on 10-August-2020.

\section{ABSTRACT}

Social media is the new tool for marketing which helps in influencing shopper's decision making process for buying goods and services. In the era of digitalisation and availability of so many social media platform marketers are now looking forward towards social media for the launching and for promotion of their products. YouTube is selected as social media platform using to influence the shoppers for this research. As in this digital era YouTube advertisements have become the major source to reach mass audience hence making YouTube to become the new marketing tool for businesses to influence the shoppers by collaborating with popular youtubers as well as by posting non skip able and skip able advertisements before the starting of any video. So the role of YouTube in influencing buying choices of shoppers was analyse with the help of secondary data, which is collected from Amity University Digital Library and Google Scholar. The data was analysed and found that people actually get influence from YouTube advertisements and it is a game changer for the businesses as by the recommendations provided by any popular youtuber for a product actually influences the people and most of the people actually end up buying the product and recommend it to their friends and family members as well.

KEYWORDS: Social media platform, Digitalisation, YouTube advertisement.

\section{INTRODUCTION}

YouTube is chosen social media platform for this research and will be studying about YouTube like what is YouTube, how it works, benefits of YouTube advertisements and what new opportunities it has provided to businesses and how it can be used as a new marketing tool by businesses.

So let's begin with -

\section{Role of internet and rise of Social media}

Over the last decade internet has grown the social media and is able to make it a mandatory part of everyone lives especially for youngster and most of the adults. Social media platform like YouTube has eliminated the age gap barrier of earning money even children can earn now with the help of their YouTube channel and has given the birth to a new field called social media influencers who has already categorised followers.

For example- JS films a biking YouTube channel with one million subscribers which means those one million people are bikers or love biking which makes it easier for a company who deal with biking equipment's to get target customer and it is a perfect opportunity to gain customers through help JS films by doing a promotion on JS films channel.

So from just sharing photos with friends and family, social media has evolved and is more impactful, mainly when it comes to business. Social media is an influential factor in the online 
market. Now a day's shoppers have a habit of following latest trends and purchase goods as per the social trends. It provides businesses a way to influence and interact with potential buyers.

\section{Here are some points: -}

\section{Improved Search Engines}

Google has totally changed the game in this world of internet. Searching for information on the internet is such an easy task and with the help of JIO it has reached in every corner of the country. So in order to expand the companies should use keywords in their post along with all the necessary details to reach their target audience in order to gain customers. As people who search for keywords related to their post on the social media will directly come in contact with their post and company.

\section{Understanding the interest of customers}

When a brand posts content which their customers like, customer spend more time on that brand post and page. Always keep your fingers on the social media pulse of your customer base, staying updated in advanced about on going trends and the upcoming trends is always considered profitable.

\section{Promotion of discounts and offers}

Every shopper is using social media and it is a part of their daily routine. So companies should advertise on these social media platforms about their upcoming sales and offers.

\section{Presence over Social Media}

The presence of a business on social media has an effective influence on buying behaviour of customer. A brand gets a lot of attention when it makes strong presence on social media. However, social media was started as a platform where people can share photos and chat with their friends and family, now social media has become much more powerful platform especially for businesses. Social media now plays a very vital role in organizations marketing strategies because of its huge reach to the people.

For example- Companies like Flipkart and Amazon are seeking the help of social media platforms to reach to masses and are dealing worldwide through these social media platforms.

Now let's understand the chosen social media platform i.e. YouTube

\section{What is YouTube?}

YouTube is basically a platform provided to each and every individual who so ever is interested in sharing his or her content or knowledge from any field or related to anything. It has no particular guidelines, categories or set rules for Uploading your content.

\section{YouTube Mission}

Mission of this platform is to provide every individual a voice by which they can share their knowledge, skills and experiences with the world. This platform believes that every person deserves to have a voice and the world should hear it and should value the opinion of every individual.

\section{Main elements which defines YouTube are: -}

$>$ Freedom to express: -

It means that they want to provide freedom to speak, share opinions, promote open dialogue to each and every individual and this creative freedom will open the doors for new opportunities.

Freedom to share Information: -

It states that everyone should have easy access to information, as video content is a powerful medium for sharing knowledge and educating people. By this every individual will get an easy access to information and skills which they want to learn.

$>$ Freedom for Opportunity: -

It actually states that every individual should have a fair chance to get noticed by their work, to become a self made individual creator, build a business and to be successful which is possible on this platform.

> Freedom of Belongingness: -

It means that every individual should be able to find communities and people which have similar interest and get connected easily without any restrictions or barriers so that they can come together and can do group projects and can help their community to grow. Moreover, they can guide, train and help the people of their community to grow and build up their skills and knowledge so that they can also get professional which will ultimately lead to the overall growth and development of their community. For Example: - Indian hip hop community. 


\section{YouTube a new tool of Marketing.}

YouTube is the second largest search engine which is globally used as a promotional tool and it can be used by any organisation working on small or large scale. In this era of digitalisation, YouTube is one of the major platform used for sharing content and uploading videos for ad campaigning to influence the buying choices of customers by promoting the product and services offered by an organisation through ad campaigns.

YouTube video or ad campaign is the latest and trending strategy which is developed by companies for enhancing the sales numbers of business. As today's generation and even most of the elderly people are watching YouTube videos for purposes such as cooking, how to repair phone, how to control hair loss etc. Which creates a good opportunity for companies to showcase the services offered by them. It can be used for answering all questions and queries of customers by communicating the benefits and how to use a particular service or product offered by the company.

Popular YouTube channel or popular youtubers have a positive impact on business profitability as companies can collaborate with them and can do paid promotion as these youtubers can showcase the product unboxing and actual functioning of the product or service and can communicate the benefits of using products and services offered by the company.

\section{Why companies are choosing YouTube as a Marketing tool?}

No doubt YouTube is one of the biggest social media platform with huge audience just click away and it is an easy way to get connected with the large number of people. It is great platform for sharing information and content and the world can easily access it from anywhere at anytime.

Moreover, it is also used as public relation tool by the companies. Companies like Google is on YouTube and they run their online digital garage courses videos on their YouTube channel which is free for the public anyone can access it anytime from anywhere. The owner of Microsoft i.e. Bill gates himself is on YouTube and run a YouTube channel by the name Bill Gates where he shares his knowledge and encourages people to grow and develop their knowledge by recommending books and sharing his experiences. However, YouTube has given this power to every individual to become a youtuber and express and shares their knowledge and views and YouTube has given their voice a power to reach to the world.

Also the most popular music company of India i.e. Tseries have the number one channel in the world of YouTube with the most number of subscriber, which are 138 million subscribers which is definitely a huge number to achieve and the number of subscribers are increasing day by day. So this shows the actual power of YouTube for a business.

As YouTube has no barrier or restrictions for opening YouTube channel which has allowed people to share their content related to anything freely on their YouTube channel which has fortunately differentiated audiences on the basis of interest as well as taste and preferences as per content provided by the youtuber, like tech channel will have audiences who have interest in new gadgets and want to know about upcoming technology. This made it easier for the companies to reach their target audiences.

Especially cosmetics companies, smartphone companies, automobile companies, clothing companies and other companies are collaborating with YouTube for running their ads on YouTube videos. They are also collaborating with popular youtubers and various popular YouTube channels and using their channel to promote their product and services and to even communicate about their latest offers, discounts, etc.

For example - Every smartphone companies running in India get associated with Indian youtubers running their tech channel. Technicalguruji is the most famous tech channel in India and every smartphone companies get collaborate with him and provide him latest smartphone straight after launch in India and in most of the cases even before the launch. He does the latest unboxing of the smartphone, one plus has even provided him their limited edition smartphone for unboxing as well.

By doing this companies get directly connected with their target audience and their product information and offers immediately get share with the masses.

Here are some of the benefits of using YouTube -

\section{Option of non skip able advertisements}

These video ads are basically ads which the user cannot skip and has to watch the complete advertisement. It can be inserted before, during, or after the main video and the user must have to watch this advertisement in order to watch his/her main YouTube video. This kind of advertisement 
technique can be used while just starting to build your customers.

\section{Analysing Results}

Google is the owner of YouTube platform so it is easier for the companies to manage their YouTube advertisements as well as can easily analyse the results of their advertisement campaign whether it is successful or not, likes and dislike ratio, number of shares of your ad, average screen time of audience. As google analytics make it easier for companies to gather the information and analyse the results.

\section{Better than Traditional method}

In the era of digitalisation, traditional TV ads on TV channels are now back dated as watching advertisements at big black screens at home or office will not be a great investment for your marketing budget as TV ads has airtime which does not provides hundred percent guarantee of success when compared with YouTube ads. Nowadays, people are more engage with their phone screen and laptops moreover people have habit to switch between other TV channels or like to spend that advertisement time on some other activity while watching television.

Also YouTube advertisement is cheaper than TV advertisement as well as it provides better engagement of audiences as compared to TV advertisements.

\section{Higher Interactivity and engagement}

YouTube have large number of active users, which is increasing day by day! Nowadays every individual have easy access to internet and people are more engage with their mobile screens and laptops or tablets. Moreover, Indian company Tseries owns the biggest channel on YouTube with the largest number of subscribers i.e. 138 billion which is increasing day by day. So this is one of the biggest proof of the engagement of YouTube audiences especially in India.

\section{REVIEW OF LITERATURE}

RinabiTanamal (2019) - Information is the core ability of an advertisement to inform the customer about the product or service and offers in order to create awareness of product or service in the market. Information is the most important aspect of advertisement by which consumers get to know about new products, such as product benefits and comparative product information.
Betsy McLeod (2017) - As unfortunately traditional TV ads is an old strategy, big black screens at home or office may not be the best investment of your marketing budget as people are now more engage with their social media platforms and YouTube where they listen to music, watch movies and even learn and gain knowledge. So businesses should move towards online advertisements.

Larry Kim (2018)- YouTube advertising is a better source of consistent return on investment than TV ads and found YouTube had a greater return on investment as it has more engaged audience on its platform.

Matt Brittin (2016) - He is Google's top ranking executive, and he stated a report analysing ad campaigns across eight countries that show in $80 \%$ of cases YouTube ads were far more effective than TV ads in driving sales. However, it doesn't mean to put off the TV forever but to supplement TV ads along with digital ads.

Barton, K. M. (2009) - As traditional medium TV advertisements have airtime which does not give hundred percent guarantee of success. Where as YouTube ads, there is no minimum investment as well as we have more chances to get attention and optimum results as audiences is more engaged moreover they like to listen and watch their favourite youtubers and their channel as well.

Liu Yuping (2011) - social media is the right platform for advertising as it used by people globally. And it is an easy way to promote products and to reach to the target audience as people have information just a click away are more engaged in using social media platforms.

Cen Wang (2015) - Collaboration with youtubers for product promotion builds the trust among the audience as the recommendation of product is directly coming from their trusted youtuber.

ElizavetaZaitceva (2017) - YouTube provides video access, sharing videos which leads to an incomparable opportunity for engagement of audience. Picture, sound, and motion helps to build an emotional involvement with the content which is only possible on YouTube. Also you can monitor your engagement through evaluating shares, comments, and likes with your video ads by promoting them on YouTube.

Neil K. (2018) - Google provides the platform of YouTube Ads where it is possible to track your results as well as analyse it. Know about your ad campaign with the help of the google analytics which can even help to know the number of people 
sharing your advertisement, average screen time of audience likes and dislikes of audiences.

\section{Methodology}

The study is basically based on the secondary data which contains of quantitative data.

\section{OBJECTIVE OF THE STUDY}

- Effects of YouTube ads on shoppers buying choices.

- To understand effectiveness of YouTube as a marketing tool.

In order to achieve these set objectives secondary data was collected. And the data was used to analyse recommendation, limitations and outcome of research.

\section{Sources of Data collection}

- Articles

- Journals

- Internet (google scholar, amity university digital library, think with google)

\section{RESULTS}

In this chapter observation and analysis of the secondary data which was collected will be discussed and the data was collected from the various research papers and articles which are mentioned in the references. The analysis of data will be lead to the achievement of research objectives.

\section{Data analysis: -}

For the topic "Can social media influence the buying choices of shoppers" various research paper and articles were studied. Let's begin with Cen Wang research paper i.e. "Do people purchase what they viewed on YouTube" in which Cen Wang stated that collaboration with popular youtubers is a good strategy for a business in order to promote their product as the company can provide a free sample to the youtuber and he/she can showcase live testing of the product as well as of its uses and benefits of purchasing the product on his/her YouTube channel which will directly get shared to huge audience and on the other hand that product recommendation is coming from the youtuber on whom audiences has trust so it will build a good product image in the eyes of consumer's as their trusted youtuber is recommending it. Mostly people ends up purchasing the product as they have seen the functioning, uses and benefits purchasing the product and all the other necessary information from the youtuber they follow.

ElizavetaZaitceva in her research paper "The fight for customer's attention: YouTube as an advertisement platform" she stated that in this era of digitalisation people are more engage in their mobile phone as they are just a click away from any information and people have easy access to internet on their phone so people are actively using YouTube for entertainment, information etc. So it is an essential strategy to do YouTube advertisements for business as YouTube has more engaged audience than behind the TV screens.

Matt Brittin is European Google's top executive claimed that YouTube advertisements are $80 \%$ more effective to engage audience than TV advertisements also YouTube advertisements are much cheaper than TV advertisements.

Larry Kim in his study "Advertising guide to YouTube" found that YouTube advertisements has provided more return on investment than TV advertisements as there is more engaged audience on YouTube as people tend to switch the channels when its an ad break on TV on the other hand YouTube provide the option of non skip able ads before consumer start to watch a video. So audience has to stick with YouTube ads and have to watch the complete advertisements.

Think with google article named "The curious consumer: Researching everything" stated that with the growth of internet facilities and access to tons of information just a click away, So the consumers are now obsessed with doing research before making any decision like from purchasing of cosmetics, electronic products to anything they want to buy as it make them more comfortable to buy the product and people are now obsessed with the product review and unboxing videos.

\section{v. DISCUSSION}

As per the analysis of data it was found that in this era of digitalisation almost every individual has access to internet and are active users of YouTube.People like to watch product reviews videos on YouTube as it makes them more comfortable are more convinced to buy those products which are recommended by the youtubers they follow as they have trust on them and find their reviews as honest opinions which easily influence buying choice of the shoppers. Moreover, YouTube advertisements are more 
effective than television advertisement as nowadays people stick more to their mobile screens than TV screens. And YouTube advertisements are much cheaper than TV advertisements and provide great return on investment than TV advertisements which are more effective and beneficial for marketing budget of any business. The aim of this research was to understand "Can social media influence the buying choices of shoppers" under which YouTube was selected as the social media platform for the research.

So conclusion can be made from the secondary data collected and analysed that are First of all it is clear that YouTube is a great tool for marketing as it has many active users and people prefer to watch product review videos before buying that product also they use YouTube to get updated with latest information and about the new products available in the market. Secondly people are more engaged in YouTube advertisements as YouTube provides the option of non skip able ads before the starting of any videos which the users cannot skip. And on the other hand people have habit to switch between channels while ads break on TV. Last but not the least mostly people purchases the products that are recommended by the youtubers they follow.

\section{RECOMMENDATIONS AND LIMITATIONS Recommendations}

In order to collaborate with a YouTube channel or a youtuber do check his/her content quality, purpose and mission of their YouTube channel as well as image and goodwill of channel in the eyes of people, along with engagement of audiences and number of subscribers. Whenever you create a video ad for YouTube do ensure that video ad should be informative and entertaining for the audience so that they get to know what you are providing and get aware of your product or service as well they should get entertained while watching your video ad and most the important thing the ad should be relevant to the product or service you are providing so that people can easily relate it with your product or service.In order to make your advertisement interesting, informative and more influencing just collaborate with a youtuber and share your product or service information and ideas of advertising and other important information you want to give it to public and let the youtuber make the video ad for you as per taste and preferences of his/her audience.

\section{Limitations}

YouTube advertisement has so many benefits but it has some limitations as well. Firstly, YouTube advertisement has an option of skipping the advertisement by which people can easily neglect the advertisement. Moreover, people hate to watch irrelevant content videos ad or any fake information provided by any youtuber regarding your product or service which can lead to losing of customer trust and loyalty towards your brand so make ensure that youtuber make relevant video ad and should only provide genuine information regarding your product or service.

Also companies should make ensure that their advertisement or youtuber they are collaborating do not hurt anyone's sentiments and emotions and do not showcase any sensitive content which can create social issue and can spread hate in the society because it will effect the company image in the eyes of public.

\section{Future scope of the research}

"Can social media influence the buying choices of shoppers" is the topic of the research under which YouTube is chosen social media platform which was analysed that how it is influencing buying choices of shoppers.Therefore, it is found that large number of people are using YouTube for gaining information, knowledge and to get entertained. Which make these audiences more engage with YouTube than on TV. As it can be used by anyone, anywhere and anytime on their phone. Moreover, it has become a marketing tool for the businesses and number of YouTube users is increasing day by day and YouTube itself is also adding new features in its platform. So to cope up with the technology advancements, latest trends and for timely upgrading the marketing strategies for businesses further study can be conducted related to other social media platforms. 